Review began 08/03/2021 Review ended 09/01/2021 Published 09/19/2021

(๑) Copyright 2021

Sinha et al. This is an open access article distributed under the terms of the Creative Commons Attribution License CC-BY 4.0. which permits unrestricted use, distribution, and reproduction in any medium, provided the original author and source are credited.

\section{Efficacy and Safety of Acotiamide Versus Mosapride in Patients With Functional Dyspepsia Associated With Meal-Induced Postprandial Distress Syndrome: A Phase III Randomized Clinical Trial}

\author{
Shubhadeep Sinha ${ }^{1}$, Sreenivasa Chary ${ }^{1}$, Pankaj Thakur ${ }^{1}$, Leela Talluri ${ }^{1}$, Mohan Reddy ${ }^{1}$, Gautam S. K ${ }^{2}$, \\ Jagan M. Mohan ${ }^{3}$, Pankaj Jain ${ }^{4}$, Sunil Naik ${ }^{5}$, Srinivas V. C. Reddy ${ }^{6}$ \\ 1. Clinical Development and Medical Affairs, Hetero Labs Limited, Hyderabad, IND 2. Internal Medicine, Shri Ganesh \\ Shankar Vidyarthi Memorial Medical College, Kanpur, IND 3. Gastroenterology, New Government General Hospital, \\ Siddhartha Medical College, Vijayawada, IND 4. Internal Medicine, Sterling Hospital, Vadodara, IND 5. General \\ Medicine, Rajiv Gandhi Institute of Medical Sciences, Srikakulam, IND 6. Department of Medicine, King George \\ Hospital, Andhra Medical College, Vishakhapatnam, IND
}

Corresponding author: Leela Talluri, leela.t@heterodrugs.com

\begin{abstract}
Background: Acotiamide is a novel prokinetic drug that acts by enhancing the release of acetylcholine and is used in the treatment of functional dyspepsia-postprandial distress syndrome (FD-PDS). Mosapride is indicated to FD-PDS as per the Rome III treatment guidelines. Mosapride $5 \mathrm{mg}$ three times daily (TID) is approved by the Drugs Controller General of India (DCGI) for the treatment of FD-PDS. The objective of this study was to determine the efficacy and safety of Acotiamide in comparison with Mosapride on FD-PDS.

Methods: The 220 patients of either gender (aged 18-64 years) with active PDS included in the study were centrally randomized 1:1 to receive either $100 \mathrm{mg}$ Acotiamide (test product) or $5 \mathrm{mg}$ Mosapride (reference product) TID for four weeks. Responder rates for the overall treatment effect (OTE) at the end of four weeks were the primary efficacy endpoint. Secondary efficacy endpoints included the elimination rate of postprandial fullness, upper abdominal bloating, and early satiation. The study also evaluated the OTE at each week, individual symptom scores, and quality of life (QoL) assessed by the Short Form-Nepean Dyspepsia Index questionnaire (SF-NDI). The safety endpoints included assessments of treatment-emergent adverse events (TEAEs).
\end{abstract}

Results: At the end of four weeks, the responders in the Acotiamide versus Mosapride group for OTE was $98 \%$ versus $93.27 \%$ in the per-protocol (PP) population. Among the intent to treat (ITT) population, the comparison of Acotiamide versus Mosapride stood at $95.15 \%$ versus $89.81 \%$. Secondary efficacy endpoints were significantly improved with $100 \mathrm{mg}$ TID Acotiamide, which was evident from the improvement in postprandial fullness (14.56\%), upper abdominal bloating (15.53\%), early satiation (10.68\%), and QoL (13.7 \pm 4.67).

Conclusions: Our study results demonstrated that Acotiamide is effective, safe, and well-tolerated and had significantly improved the QoL over a four-week treatment period in FD-PDS patients. The efficacy and safety profiles of Acotiamide were similar to Mosapride.

Categories: Family/General Practice, Internal Medicine, Gastroenterology

Keywords: functional dyspepsia, acotiamide, rome iv criteria, epigastric pain syndrome, postprandial distress syndrome, clinical trial

\section{Introduction}

According to the ROME III and the updated ROME IV criteria, functional dyspepsia (FD) is defined as the presence of one or more symptoms related to the gastroduodenal region. FD symptoms include postprandial fullness (PPF), early satiety (ES), epigastric pain, and epigastric burning in the absence of any underlying organic, systemic, or metabolic disease $[1,2]$. Globally, the prevalence of FD varies between $5 \%$ and $11 \%[3,4]$.

The pathophysiology of FD remains to be completely understood. Causes of FD could be multifactorial and may include dysfunction of sensory and motor neurons of the gastrointestinal tract, immune-related dysfunction, dysbiosis of the gut microbiome, and gut-brain axis dysfunction [5]. In addition, predisposing factors for FD also include infections with bacteria like Helicobacter pylori, Escherichia coli O157, Campylobacter jejuni, and Salmonella. Other risk factors for FD are long-term antibiotic use, therapy with non-steroidal anti-inflammatory drugs, obesity/overweight, smoking, and people with psychosocial 
disorders. Patients with FD are therefore treated with different classes of drugs including the proton pump inhibitors (PPIs), $\mathrm{H}_{2}$ receptor antagonists (H2RA), prokinetic agents, and antidepressants [6]. A recent study from Japan had recommended the use of Rikkunshito, herbal medicine, to treat FD as an alternative to the prokinetic drugs currently in use [7].

Mosapride is a 5-hydroxytryptamine (5 HT4)/serotonin receptor agonist that is widely used in the treatment of FD [8]. Mosapride facilitates both gastric and colon motility and increases gastric emptying by promoting the release of acetylcholine at nerve terminals in the mesenteric plexus [9,10]. Acotiamide, a prokinetic drug, has received its first approval in Japan for the treatment of epigastric bloating and ES in FD patients. Acotiamide exerts its activity by inhibiting the acetylcholinesterase (AChE) enzyme and resulting in enhanced release of acetylcholine at neuromuscular junctions [4,11]. This causes an increase in the force of muscle contractions and enables gastric emptying. Acotiamide acts directly on the gut and through the brain-gut axis involving the central nervous system [12]. A similar prokinetic drug, cisapride, was withdrawn from the market, and also there are limitations for the usage of other drugs with prokinetic action such as domperidone and metoclopramide. There is no drug of choice for safe and efficacious long-term usage against meal-related symptoms of FD [13]. Mosapride is an efficacious, safe, and widely used drug, and its prokinetic effect is similar to Acotiamide. Furthermore, the choice of the comparator drug, Mosapride, in this study was also made based on the recommendations of the subject expert committee (SEC), Central Drugs Standard Control Organization (CDSCO), India.

The available literature suggests several limitations concerning the therapeutic approaches to treat and manage patients with FD. Among them, limited data on the long-term efficacy and safety of drugs used to treat FD assumes increased significance. Also, it is important to understand the potential adverse effects of various therapeutic agents.

Although both Mosapride and Acotiamide are used by clinicians to treat FD patients in India and elsewhere in the world, currently, there is no consensus with regard to the performance, efficacy, and safety of both drugs in relieving the symptoms associated with FD. Therefore, this phase III clinical study was carried out to evaluate the efficacy and safety of Acotiamide in comparison with Mosapride, in Indian adult patients with FD.

\section{Materials And Methods}

\section{Study design}

This multicenter, randomized, active-controlled, parallel-group, assessor blind, phase 3 study was designed to evaluate the efficacy and safety of Acotiamide in comparison with Mosapride in patients with FD-PDS. The choice of the comparator drug was made based on the recommendations of the SEC, Gastroenterology. Also, the CDSCO, India, suggested the use of comparator drugs belonging to the same drug class and having similar prokinetic effects. The study was conducted at nine investigative sites in India from March 2016 to August 2016. The trial was registered with Clinical Trial Registry-India (CTRI/2016/03/006763) before enrolment of the first patient in the study. The study was initiated after obtaining approval of CDSCO and IRB/IEC of each participating study center.

\section{Inclusion and exclusion criteria}

Patients of either gender aged $\geqslant 18$ years to $\leqslant 64$ years and diagnosed with FD-PDS as per the Rome III classification were included in the study. Patients with only epigastric pain syndrome were included if the symptoms causing distress were meal-related at the time of enrolment. All the patients underwent upper abdominal endoscopy at the time of screening to rule out any abnormalities in the esophagus, duodenum, or stomach.

Patients with a history of heartburn within 12 weeks; diabetes mellitus requiring treatment; severe abnormality in the electrocardiogram; serious depression or anxiety disorder; biliary tract disease and/or pancreatitis; irritable bowel syndrome; presence of any symptom indicating serious or malignant disease; clinically significant metabolic, hepatic, renal, or hematological disorders; and drug or alcohol abuse were excluded. After the baseline period, anti-secretory drugs, prokinetics, antacids, non-steroidal antiinflammatory drugs, and antidepressant drugs were not allowed.

\section{Randomization}

The study comprised a maximum of one week of screening and baseline period followed by four weeks of the treatment period. During the baseline period, patients were given diaries to mark their symptoms with severity on each day to determine the study eligibility. Randomization was performed based on a computergenerated randomization sequence and by using statistical software. Eligible patients were assigned a unique patient ID and treatment regimen given in the ratio of $1: 1$. The patients in each group received either Acotiamide $100 \mathrm{mg}$ (test product) or Mosapride $5 \mathrm{mg}$ (comparator drug) three times daily (TID) as per the central randomization schedule followed throughout the study centers. 


\section{Cureus}

\section{Efficacy and safety endpoints}

Responder rates based on overall treatment effect (OTE) by using a seven-point Likert scale at the end of treatment visit was the primary efficacy endpoint [14]. On the OTE scale, patients with "extremely improved" or "improved" were considered as responders. Secondary endpoints included OTE by using a seven-point Likert scale at each week; elimination rate of upper abdominal bloating, postprandial fullness, and ES at the end of treatment visit; the improvement of individual symptoms score on a severity scale of 03 (none, mild, moderate, and severe) at each week and by using Short Form-Nepean Dyspepsia Index questionnaire (SF-NDI) for improvement in disease-specific quality of life (QoL) [15]. Safety variables included all treatment-emergent clinical and laboratory adverse events (TEAEs).

\section{Statistical analysis}

The sample size was calculated considering a responder rate (OTE) of 52\% of the reference product (as per published literature) and assuming no difference in the proportion of OTE between test (Acotiamide 100 $\mathrm{mg}$ ) and reference (Mosapride $5 \mathrm{mg}$ ) products. To confirm the non-inferiority of test (Acotiamide $100 \mathrm{mg}$ ) product to reference (Mosapride $5 \mathrm{mg}$ ) product, with $80 \%$ power, 0.025 level of significance, and a noninferiority margin of $-20 \%$ of the control value, a sample size of at least 99 evaluable patients were required per group, i.e., about 198 patients. Assuming a dropout rate of approximately 10\%, about 220 subjects were required to be enrolled in the study with a 1:1 treatment allocation ratio in test and reference arms. All continuous demographic parameters were summarized using numbers, mean, median, standard deviation, range, and quartiles. Fisher's exact test was used to compare proportions like males/females. The primary and secondary endpoints were analyzed using the Chi-square test and comparison between groups by using t-test. Adverse events were coded using Medical Dictionary for Regulatory Activities (Med DRA Version 19.1). The incidence of serious adverse events was compared across the treatment groups using Fisher's exact test. SAS ${ }^{\circledR}$ Version 9.4 (SAS Institute Inc., USA) was used to perform all statistical analyses.

\section{Results}

\section{Patient disposition and characteristics}

A total of 220 patients with FD-PDS as defined by the Rome III criteria were enrolled and randomized in a $1: 1$ ratio to receive either Acotiamide $100 \mathrm{mg}(\mathrm{n}=108)$ or Mosapride $5 \mathrm{mg}(\mathrm{n}=112)$ TID before meals (Figure 1).

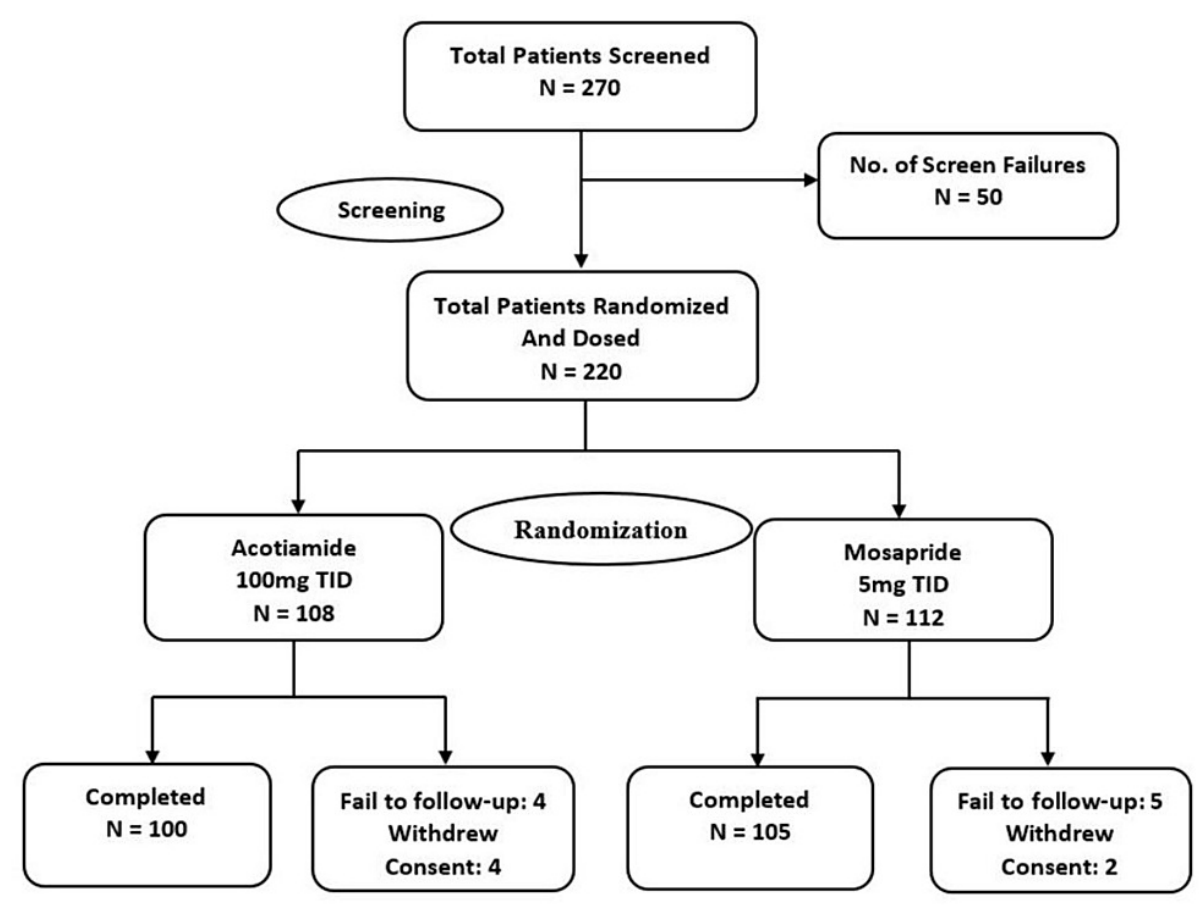

FIGURE 1: Patient disposition

ITT population consisted of 218 (99.1\%) patients (107 [99.1\%] in the Acotiamide group and 111 [99.1\%] patients in the Mosapride group, respectively), and PP population consisted of 204 (92.7\%) patients (100 [92.6\%] patients in the Acotiamide group and 104 [92.9\%] patients in the Mosapride group, respectively). Safety analyses were conducted for all enrolled patients. The demographic characteristics of patients were similar between both treatment groups and are summarized in Table 1 . 


\section{Cureus}

\begin{tabular}{|c|c|c|c|}
\hline Characteristics & Acotiamide $(\mathrm{N}=108)$ & Mosapride ( $\mathrm{N}=112)$ & p-value \\
\hline \multicolumn{4}{|l|}{ Gender } \\
\hline Male & $2(1.9 \%)$ & $3(2.7 \%)$ & \multirow{2}{*}{$1.0000^{*}$} \\
\hline Female & 106 (98.1\%) & 109 (97.3\%) & \\
\hline Age (years) & $38.1 \pm 11.44$ & $37.8 \pm 11.56$ & $0.8567^{* *}$ \\
\hline Height $(\mathrm{cm})$ & $161.40 \pm 8.02$ & $162.01 \pm 8.10$ & $0.5749^{* \star}$ \\
\hline Weight (kg) & $59.61 \pm 9.31$ & $60.26 \pm 10.65$ & $0.6306^{\star \star}$ \\
\hline BMI $\left(\mathrm{kg} / \mathrm{m}^{2}\right)$ & $22.865 \pm 3.227$ & $23.006 \pm 4.040$ & $0.7765^{\star *}$ \\
\hline
\end{tabular}

\section{TABLE 1: Demographic and baseline characteristics of the patients}

Data are shown as mean \pm SD or $n(\%)$.

*p values are obtained by performing Fisher's exact test.

** $p$ values are obtained by performing a t-test.

\section{Primary efficacy endpoint}

The responder rate was $98 \%$ and $93.27 \%$ (PP population) and $95.15 \%$ and $89.91 \%$ (ITT population) in the Acotiamide and Mosapride groups, respectively, at the end of treatment visit (four weeks). A significant difference in the performance of both the drugs became apparent from second week. The difference in proportion between groups was comparable [4.7\% $(-0.8-10.3) ; \mathrm{p}=0.1707$ and $5.2 \%(-1.8-12.3) ; \mathrm{p}=0.1954]$ in PP and ITT population, respectively (Table 2). 


\section{Cureus}

Endpoint

(A) Per-Protocol Population

\section{Primary Endpoint}

Responder rate by using OTE

98.00

Acotiamide $\mathbf{n}$

(\%)

(\%)

Difference $(95 \%$

CI)

Acotiamide vs Mosapride ( $p$ value)

\section{Secondary Endpoints Elimination Rate}

Postprandial fullness

Upper abdominal bloating

Early satiation
(B) Intent to Treat Population

\section{Primary Endpoint}

Responder rate by using OTE

89.91

$5.2(-1.8-12.3)$

0.1954

\section{Secondary Endpoints Elimination Rate}

Postprandial fullness $\quad 14.56$

Upper abdominal bloating

10.68

$-5.4(-14.1,3.3)$

0.2875

Early satiation

13.76

$-1.8(-11.3,7.8)$

0.8462

12.84

$2.2(-6.5,10.8)$

0.6744

\section{TABLE 2: Efficacy endpoints at week 4 per-protocol population and intent to treat population}

\section{Secondary efficacy endpoints}

Overall Treatment Effect (OTE)

The responder rates in PP population in the Acotiamide and Mosapride groups were $6 \%$ versus $2.88 \%[(-2.5$, $8.8) ; \mathrm{p}=0.3247)], 38 \%$ versus. $40.38 \%[(-15.8,11.0) ; \mathrm{p}=0.7751)], 87 \%$ versus $78.85 \%[(-2.1,18.4) ; \mathrm{p}=0.1398)]$ and $98 \%$ versus $93.27 \%[(-0.8,10.3) ; \mathrm{p}=0.1707)]$ each week, respectively. Responder rates in ITT population in the Acotiamide and Mosapride groups were $5.83 \%$ versus $2.75 \%[(-2.4,8.5) ; \mathrm{p}=0.3215)], 36.89 \%$ versus $39.45 \%[(-15.6,10.5) ; \mathrm{p}=0.7776)], 84.47 \%$ versus $76.15 \%[(-2.3,18.9), \mathrm{p}=0.1676)]$, and $95.15 \%$ versus $89.91 \%$ ( $95 \% \mathrm{CI}$ is $-1.8,12.3 ; \mathrm{p}=0.1954)$ at each week, respectively.

Elimination Rate

The elimination rate (post-prandial fullness, upper abdominal bloating, and ES) at week 4 in the Acotiamide and Mosapride groups were $15 \%$ versus $9.62 \%[(-14.4,3.6) ; \mathrm{p}=0.2883)], 16 \%$ versus $14.42 \%[(-11.4,8.3) ; \mathrm{p}=$ $0.8460)], 11 \%$ versus $13.46 \%[(-6.5,11.4) ; \mathrm{p}=0.6718)]$ in PP population and $14.56 \%$ versus $9.17 \%$ [(-14.1, $3.3) ; \mathrm{p}=0.2875)], 15.53 \%$ versus $13.76 \%[(-11.3,7.8) ; \mathrm{p}=0.8462)]$, and $10.68 \%$ versus $12.84 \%[(-6.5,10.8) ; \mathrm{p}=$ $0.6744)]$ in ITT population. The elimination rates were comparable between both the treatment groups (Table 2).

Improvement of Individual Symptom Scores

There was a notable improvement in both Acotiamide and Mosapride groups in individual symptom severity on a severity scale of 0 to 3 (none, mild, moderate, and severe) each week. There was no significant difference observed for the difference in improvement rates in individual symptom severity between the Acotiamide and Mosapride groups (Table 3). 


\section{Cureus}

\begin{tabular}{|c|c|c|c|c|c|c|c|c|c|c|}
\hline \multirow{3}{*}{ Parameter } & \multicolumn{5}{|l|}{ PP Population } & \multicolumn{5}{|l|}{ ITT Population } \\
\hline & \multirow{2}{*}{$\begin{array}{l}\text { Acotiamide [N = } \\
100] \text { Mean } \pm \text { SD }\end{array}$} & \multirow{2}{*}{$\begin{array}{l}\text { Mosapride }[N= \\
104] \text { Mean } \pm \text { SD }\end{array}$} & \multicolumn{3}{|c|}{ Acotiamide vs Mosapride } & \multirow{2}{*}{$\begin{array}{l}\text { Acotiamide }[N= \\
107] \text { Mean } \pm \text { SD }\end{array}$} & \multirow{2}{*}{$\begin{array}{l}\text { Mosapride }[N= \\
111] \text { Mean } \pm \text { SD }\end{array}$} & \multicolumn{3}{|c|}{ Acotiamide vs Mosapride } \\
\hline & & & $\begin{array}{l}\text { Mean } \\
\text { difference }\end{array}$ & $\begin{array}{l}95 \% \\
\mathrm{Cl}\end{array}$ & $\begin{array}{l}\text { p- } \\
\text { value }\end{array}$ & & & $\begin{array}{l}\text { Mean } \\
\text { difference }\end{array}$ & $\begin{array}{l}95 \% \\
\mathrm{Cl}\end{array}$ & $\begin{array}{l}\mathrm{p}- \\
\text { value }\end{array}$ \\
\hline $\begin{array}{l}\text { Upper abdominal } \\
\text { pain }\end{array}$ & $1.8 \pm 2.36$ & $2.3 \pm 2.78$ & -0.31 & $\begin{array}{l}-1.8 \\
-1.1\end{array}$ & 0.1385 & $2.0 \pm 2.63$ & $2.6 \pm 3.13$ & -0.41 & $\begin{array}{l}-1.8 \\
-1.0\end{array}$ & 0.0954 \\
\hline $\begin{array}{l}\text { Upper abdominal } \\
\text { discomfort }\end{array}$ & $0.4 \pm 0.37$ & $0.5 \pm 0.40$ & -0.06 & $\begin{array}{l}-0.3 \\
-0.2\end{array}$ & 0.1210 & $0.4 \pm 0.43$ & $0.5 \pm 0.43$ & -0.07 & $\begin{array}{l}-0.3 \\
-0.2\end{array}$ & 0.1549 \\
\hline $\begin{array}{l}\text { Postprandial } \\
\text { fullness }\end{array}$ & $0.5 \pm 0.37$ & $0.5 \pm 0.39$ & -0.08 & $\begin{array}{l}-0.3 \\
-0.1\end{array}$ & 0.2718 & $0.5 \pm 0.41$ & $0.6 \pm 0.48$ & -0.11 & $\begin{array}{l}-0.3 \\
-0.1\end{array}$ & 0.1416 \\
\hline $\begin{array}{l}\text { Upper abdominal } \\
\text { bloating }\end{array}$ & $0.4 \pm 0.37$ & $0.5 \pm 0.45$ & 0.03 & $\begin{array}{l}-0.1 \\
-0.2\end{array}$ & 0.6627 & $0.5 \pm 0.44$ & $0.5 \pm 0.52$ & 0.01 & $\begin{array}{l}-0.2 \\
-0.2\end{array}$ & 0.5608 \\
\hline Early satiation & $0.5 \pm 0.41$ & $0.5 \pm 0.45$ & -0.13 & $\begin{array}{l}-0.3 \\
-0.0\end{array}$ & 0.4363 & $0.5 \pm 0.47$ & $0.6 \pm 0.50$ & -0.13 & $\begin{array}{l}-0.3 \\
-0.0\end{array}$ & 0.4234 \\
\hline $\begin{array}{l}\text { Excessive } \\
\text { belching }\end{array}$ & $0.2 \pm 0.36$ & $0.2 \pm 0.34$ & -0.08 & $\begin{array}{l}-0.3 \\
-0.2\end{array}$ & 0.8176 & $0.3 \pm 0.39$ & $0.3 \pm 0.39$ & -0.10 & $\begin{array}{l}-0.3 \\
-0.1\end{array}$ & 0.5538 \\
\hline Nausea & $0.1 \pm 0.23$ & $0.1 \pm 0.21$ & -0.09 & $\begin{array}{l}-0.3 \\
-0.1\end{array}$ & 0.2591 & $0.1 \pm 0.26$ & $0.2 \pm 0.24$ & -0.10 & $\begin{array}{l}-0.3 \\
-0.1\end{array}$ & 0.2003 \\
\hline Vomiting & $0.1 \pm 0.17$ & $0.1 \pm 0.16$ & -0.07 & $\begin{array}{l}-0.2 \\
-0.0\end{array}$ & 0.3984 & $0.1 \pm 0.22$ & $0.1 \pm 0.19$ & -0.08 & $\begin{array}{l}-0.2 \\
-0.0\end{array}$ & 0.2723 \\
\hline Heartburn & $0.1 \pm 0.20$ & $0.1 \pm 0.21$ & -0.01 & $\begin{array}{l}-0.2 \\
-0.2\end{array}$ & 0.9973 & $0.1 \pm 0.23$ & $0.1 \pm 0.21$ & -0.01 & $\begin{array}{l}-0.2 \\
-0.1\end{array}$ & 0.9488 \\
\hline $\begin{array}{l}\text { Total individual } \\
\text { symptoms score }\end{array}$ & $2.2 \pm 1.90$ & $2.5 \pm 1.96$ & -0.50 & $\begin{array}{l}-1.5 \\
-0.6\end{array}$ & 0.2700 & $2.5 \pm 2.28$ & $2.8 \pm 2.37$ & -0.59 & $\begin{array}{l}-1.6 \\
-0.5\end{array}$ & 0.2229 \\
\hline
\end{tabular}

TABLE 3: Individual symptom severity score (ISSS) - change from baseline to week 4 in ITT and PP population

$\mathrm{N}$, Total number of subjects; ITT, intent to treat; PP, per-protocol population.

\section{Quality-of-life scores}

The change in SF-NDI scale score in the Acotiamide and Mosapride groups was - 13.9 versus -12.8 in the PP population and -13.7 versus -12.4 in the ITT population (Table 4). Based on the SF-NDI scores, the QoL had significantly improved $(\mathrm{p}<.0001)$ compared to baseline. The difference in SF-NDI scores [-1.15 $(-2.4-0.1), \mathrm{p}$ $=0.0693)$ in PP population and [-1.37 (-2.7 - 0.1), $\mathrm{p}=0.0347)]$ in ITT population was comparable between Acotiamide and Mosapride. 


\section{Cureus}

\begin{tabular}{|c|c|c|c|c|}
\hline \multirow{3}{*}{ Variable } & \multicolumn{4}{|c|}{ Change from baseline to Week 4 for SF-NDI (Score), mean \pm SD } \\
\hline & \multicolumn{2}{|l|}{ PP Population ( $N=204$ ) } & \multicolumn{2}{|l|}{ ITT Population ( $\mathrm{N}=\mathbf{2 1 8}$ ) } \\
\hline & Acotiamide $(\mathrm{N}=100)$ & Mosapride $(\mathrm{N}=104)$ & Acotiamide $(N=107)$ & Mosapride $(\mathrm{N}=111)$ \\
\hline Overall symptom score & $-13.9 \pm 4.64$ & $-12.8 \pm 4.71$ & $-13.7 \pm 4.67$ & $-12.4 \pm 4.94$ \\
\hline Tension & $-1.6 \pm 0.69$ & $-1.4 \pm 0.63$ & $-1.5 \pm 0.71$ & $-1.4 \pm 0.66$ \\
\hline Interference with daily activities & $-3.2 \pm 1.29$ & $-3.0 \pm 1.22$ & $-3.1 \pm 1.30$ & $-2.9 \pm 1.28$ \\
\hline Eating/Drinking & $-3.2 \pm 1.27$ & $-2.9 \pm 1.36$ & $-3.2 \pm 1.28$ & $-2.8 \pm 1.40$ \\
\hline Knowledge/Control & $-3.0 \pm 1.35$ & $-2.8 \pm 1.39$ & $-3.0 \pm 1.36$ & $-2.7 \pm 1.40$ \\
\hline Work/Study & $-2.9 \pm 1.30$ & $-2.7 \pm 1.32$ & $-2.9 \pm 1.32$ & $-2.6 \pm 1.35$ \\
\hline
\end{tabular}

TABLE 4: Summary of overall and subscale symptom scores on the Short Form-Nepean Dyspepsia Index (SF-NDI) questionnaire

$\mathrm{N}$, Total number of subjects; ITT, intent to treat; PP, per protocol; p-value $<0.0001$.

\section{Safety}

Overall, three adverse events (AEs) were reported in three patients receiving Acotiamide, and two adverse events were reported in two patients in the Mosapride group. All the five AEs were mild in severity, unlikely related to the study drug, wherein the subjects recovered without any sequelae (Table 5).

\begin{tabular}{|c|c|c|c|}
\hline System Organ Class Preferred Term & Acotiamide $[\mathrm{N}=108] \mathrm{n}(\%)$ & Mosapride [N = 112] n (\%) & Overall $[\mathrm{N}=220] \mathrm{n}(\%)$ \\
\hline Any treatment-emergent adverse event & $3(2.8)$ & $2(1.8)$ & $5(2.3)$ \\
\hline \multicolumn{4}{|l|}{ Nervous system disorders } \\
\hline Headache & $1(0.9)$ & $1(0.9)$ & $2(0.9)$ \\
\hline Dizziness & 0 & $1(0.9)$ & $1(0.5)$ \\
\hline \multicolumn{4}{|l|}{ Skin and subcutaneous tissue disorders } \\
\hline Pruritus & $2(1.9)$ & 0 & $2(0.9)$ \\
\hline
\end{tabular}

TABLE 5: Overall summary of treatment-emergent adverse events - safety population

\section{Discussion}

FD is a common disorder that affects the upper digestive tract. It is a highly prevalent chronic gastrointestinal disorder that considerably lowers the QoL of affected patients and leads to frequent medical consultations [16]. The prevalence of FD among the communities may be higher than $20 \%$. The symptoms associated with FD include epigastric pain, burning sensation, bloating, postprandial fullness, blanching, bloating, and nausea. Most affected people include those aged over 60 years as compared to young people and those who are potentially infected with Helicobacter pylori [17,18]. In general, FD patients are treated with proton pump inhibitors (omeprazole, esomeprazole, lansoprazole, dexlansoprazole, pantoprazole, and rabeprazole), neuromodulators (tricyclic antidepressants, serotonin reuptake inhibitors, serotonin noradrenaline reuptake inhibitors, and noradrenergic and specific serotonergic antidepressant), and prokinetic drugs (metoclopramide, cisapride, domperidone, ranitidine, Mosapride, metoclopramide, trimebutine, itopride, and Acotiamide) [19,20,21].

Currently, the recommended first-line treatments for FD are acid-suppressive or prokinetic drugs [22]. While prokinetics are recommended as initial therapy for treating PDS, there is still no consensus regarding the drug of choice $[23,24]$. Acotiamide is a prokinetic drug that has recently been approved in Japan for the treatment of FD. In phase II studies conducted in Japan and Europe, Acotiamide exerted gastroprokinetic activity, improved gastric emptying, and accommodation, thereby confirming its beneficial effects in alleviating FD symptoms that include postprandial fullness, upper abdominal bloating, and early 
satiation $[21,23]$. Improvement of FD symptoms in $93 \%$ of patients approximately after four weeks of administration of Acotiamide was reported by Behera et al. [25]. Narayanan et al. reported complete relief or significant improvement from postprandial fullness, upper abdominal bloating, and ES in $79.2 \%, 74.4 \%$, and $77.1 \%$ patients, respectively ( $p<0.001$ for all versus no/slight improvement) when treated for $>28$ days or 14-28 days with Acotiamide [26]. Matsueda et al. reported a responder rate based on the OTE by $52.2 \%$ patients receiving Acotiamide $100 \mathrm{mg}$ TID and $34.8 \%$ patients receiving placebo $(\mathrm{p}<0.001)$. At the end of four weeks, the Acotiamide group $(\mathrm{p}=0.004)$ showed improvement in all three meal-related FD symptoms. The elimination rate of all three meal-related symptoms (postprandial fullness, upper abdominal bloating, and early satiation) was $15.3 \%$ with Acotiamide and $9.0 \%$ with placebo $(\mathrm{p}=0.004)$ [27].

Interestingly, most previous clinical studies have evaluated the performance, safety, and efficacy of Acotiamide in comparison to a placebo. There have been hardly any studies that compared Acotiamide with other similar drugs in the literature. A recent meta-analysis study had evaluated the efficacy of several drugs that are currently being used to treat FD. It was noted that among all the drugs tested during the randomized control trials, Acotiamide showed greater efficacy as compared to the placebo [28]. This study also is another proof of the fact that there are scanty reports of clinical trials carried out to assess the efficacy and safety of Acotiamide in comparison with an already existing drug instead of a placebo.

The long-term safety concerns associated with the use of Acotiamide were previously investigated. It was revealed that there was no clinical or laboratory result associated with noticeable adverse effects among people even after 50 weeks of administration [13]. The results of the current study showed that Acotiamide $100 \mathrm{mg}$ TID had a consistent efficacy (OTE: 95.15\%) concerning the improvement in individual FD symptoms (postprandial fullness: $14.56 \%$; upper abdominal bloating: $15.53 \%$; and early satiation: $10.68 \%$ ). The study results also demonstrate significant improvement on all sub-domains of the disease-specific SFNDI QoL assessment (overall symptom score: $-13.7 \pm 4.67$ ), which is comparable to the comparator drug and the efficacy data of Acotiamide drug reported in the literature.

Being a functional disease, the endpoints in the study are subjective and are based on patient-reported outcomes on standardized response scales. However, the subjectivity of the response parameters could be a limiting factor in the study. Although the prevalence of the disease is widespread and often undertreated, this disease is not commonly and adequately diagnosed in the general population. Additionally, a longer duration of treatment is needed for long-term benefits.

\section{Conclusions}

FD is one of the most common upper gastrointestinal disorders and is highly prevalent worldwide. FD symptom management remains challenging, thus comprising an unmet medical need. In the present study, Acotiamide $100 \mathrm{mg}$ (hetero) TID showed a significant improvement in the QoL with consistent efficacy and safety that was comparable with Mosapride in Indian adult patients with FD. Acotiamide could be chosen as an alternative drug by physicians while treating patients with FD-PDS in India.

\section{Additional Information \\ Disclosures}

Human subjects: Consent was obtained or waived by all participants in this study. 1. Institutional Ethics Committee, Siddhartha Medical College \& Government General Hospital; 2. Institutional Human Ethics Committee, GMERS Medical College and Hospital; 3. Sterling Ethics Committee, Sterling Hospital; 4. Institutional Ethics Committee, Rajiv Gandhi Institute of Medical Sciences \& RIMS Government General Hospital; 5. Nirmal Hospital Institutional Ethics Committee; 6. Ethics Committee, Ganesh Shankar Vidyarthi Memorial (GSVM) Medical College; 7. Kanoria Ethics Committee; 8. Institutional Ethics Committee, Jeevan Jyoti Hospital \& Research Centre; 9. Institutional Ethics Committee, King George Hospital issued approval 1. ECR/633/Inst/AP/2014; 2. ECR/28/Inst/GJ/2013; 3. ECR/582/Inst/GJ/2014; 4. ECR/492/Inst/AP/2013; 5. ECR/325/Inst/UP/2013; 6. ECR/680/Inst/UP/2014; 7. ECR/620/Inst/GJ/2014; 8. ECR/285/Inst/UP/2013; 9. $\mathrm{ECR} / 197 / \mathrm{Inst} / \mathrm{KGH} / 2013$. The study was designed and conducted in accordance with the ethical principles originating in the Declaration of Helsinki and are consistent with the International Council for Harmonization Good Clinical Practice Guidelines, Schedule Y, and Indian Regulatory Laws governing biomedical research in human patients. The protocol was reviewed and approved by the regulatory authority of India (DCGI) and the Institutional Ethics Committees of participating centers. The study was registered with Clinical Trial Registry-India: CTRI/2016/03/006763 (CTRI: http://ctri.nic.in/Clinicaltrials/login.php) prior to initiation of patient screening. Patients signed an Ethical Committee-approved written informed consent before any trial procedure was initiated. Animal subjects: All authors have confirmed that this study did not involve animal subjects or tissue. Conflicts of interest: In compliance with the ICMJE uniform disclosure form, all authors declare the following: Payment/services info: All authors have declared that no financial support was received from any organization for the submitted work. Financial relationships: All authors have declared that they have no financial relationships at present or within the previous three years with any organizations that might have an interest in the submitted work. Other relationships: Shubhadeep Sinha, Sreenivasa Chary, Pankaj Thakur, Leela Talluri, and Mohan Reddy are the employees of Hetero Labs Limited, India, and they have not received any financial payments from the sponsoring study. 


\section{Acknowledgements}

Hetero Labs Limited, India, sponsored this study, and all the study-related materials including study drugs were provided by Hetero Labs Limited, India. The authors would like to thank the study investigators Dr. Jitendra Anand, Dr. Upesh A Parmar, and Dr. Sushil Tripathi as well as study staff and participants for all their support, cooperation, and valuable participation in this study. The clinical trial registry number is CTRI/2016/03/006763.

\section{References}

1. Tack J, Talley NJ, Camilleri M, Holtmann G, Hu P, Malagelada JR, Stanghellini V: Functional gastroduodenal disorders. Gastroenterology. 2006, 130:1466-79. 10.1053/j.gastro.2005.11.059

2. Stanghellini V, Chan FK, Hasler WL, Malagelada JR, Suzuki H, Tack J, Talley NJ: Gastroduodenal disorders. Gastroenterology. 2016, 150:1380-92. 10.1053/j.gastro.2016.02.011

3. Ford AC, Marwaha A, Sood R, Moayyedi P: Global prevalence of, and risk factors for, uninvestigated dyspepsia: a meta-analysis. Gut. 2015, 64:1049-57. 10.1136/gutjnl-2014-307843

4. Corsetti M, Fox M: The management of functional dyspepsia in clinical practice: what lessons can be learnt from recent literature?. F1000Res. 2017, 6:1778. 10.12688/f1000research.12089.1

5. Ford AC, Mahadeva S, Carbone MF, Lacy BE, Talley NJ: Functional dyspepsia. Lancet. 2020, 396:1689-702. 10.1016/S0140-6736(20)30469-4

6. Francis P, Zavala SR: Functional Dyspepsia. StatPearls Publishing, Treasure Island, FL; 2021.

7. Inokuchi K, Masaoka T, Kanai T: Rikkunshito as a therapeutic agent for functional dyspepsia and its prokinetic and non-prokinetic effects. Front Pharmacol. 2021, 12:640576. 10.3389/fphar.2021.640576

8. Lim HC, Kim JH, Youn YH, Lee EH, Lee BK, Park H: Effects of the addition of mosapride to gastroesophageal reflux disease patients on proton pump inhibitor: a prospective randomized, double-blind study. J Neurogastroenterol Motil. 2013, 19:495-502. 10.5056/jnm.2013.19.4.495

9. Pan H, Galligan JJ: 5-HT1A and 5-HT4 receptors mediate inhibition and facilitation of fast synaptic transmission in enteric neurons. Am J Physiol. 1994, 266:G230-8. 10.1152/ajpgi.1994.266.2.G230

10. Tonini M, Galligan JJ, North RA: Effects of cisapride on cholinergic neurotransmission and propulsive motility in the guinea pig ileum. Gastroenterology. 1989, 96:1257-64. 10.1016/s0016-5085(89)80012-5

11. Distrutti E, Fiorucci S, Hauer SK, Pensi MO, Vanasia M, Morelli A: Effect of acute and chronic levosulpiride administration on gastric tone and perception in functional dyspepsia. Aliment Pharmacol Ther. 2002, 16:613-22. 10.1046/j.1365-2036.2002.01180.x

12. Tack J, Janssen P: Acotiamide (Z-338, YM443), a new drug for the treatment of functional dyspepsia . Expert Opin Investig Drugs. 2011, 20:701-12. 10.1517/13543784.2011.562890

13. Tack J, Pokrotnieks J, Urbonas G, et al.: Long-term safety and efficacy of acotiamide in functional dyspepsia (postprandial distress syndrome)-results from the European phase 3 open-label safety trial. Neurogastroenterol Motil. 2018, 30:e13284. 10.1111/nmo.13284

14. Veldhuyzen van Zanten SJ, Chiba N, Armstrong D, et al.: Validation of a 7-point global overall symptom scale to measure the severity of dyspepsia symptoms in clinical trials. Aliment Pharmacol Ther. 2006, 23:521-9. 10.1111/j.1365-2036.2006.02774.x

15. Talley NJ, Verlinden M, Jones M: Quality of life in functional dyspepsia: responsiveness of the Nepean Dyspepsia Index and development of a new 10-item short form. Aliment Pharmacol Ther. 2001, 15:207-16. 10.1046/j.1365-2036.2001.00900.x

16. Brook RA, Kleinman NL, Choung RS, Melkonian AK, Smeeding JE, Talley NJ: Functional dyspepsia impacts absenteeism and direct and indirect costs. Clin Gastroenterol Hepatol. 2010, 8:498-503. 10.1016/j.cgh.2010.03.003

17. Harer KN, Hasler WL: Functional dyspepsia: a review of the symptoms, evaluation, and treatment options . Gastroenterol Hepatol (N Y). 2020, 16:66-74.

18. Goyal O, Nohria S, Dhaliwal AS, Goyal P, Soni RK, Chhina RS, Sood A: Prevalence, overlap, and risk factors for Rome IV functional gastrointestinal disorders among college students in northern India. Indian J Gastroenterol. 2021, 40:144-53. 10.1007/s12664-020-01106-y

19. Ahmed A, Clarke JO: Proton Pump Inhibitors (PPI). StatPearls Publishing, Treasure Island, FL; 2021.

20. Drossman DA, Tack J, Ford AC, Szigethy E, Törnblom H, Van Oudenhove L: Neuromodulators for functional gastrointestinal disorders (disorders of gut-brain interaction): a Rome foundation working team report. Gastroenterology. 2018, 154:1140-1171. 10.1053/j.gastro.2017.11.279

21. Pittayanon R, Yuan Y, Bollegala NP, Khanna R, Leontiadis GI, Moayyedi P: Prokinetics for functional dyspepsia. Cochrane Database Syst Rev. 2018, 10:CD009431. 10.1002/14651858.CD009431.pub3

22. Vanheel H, Tack J: Therapeutic options for functional dyspepsia . Dig Dis. 2014, 32:230-4. $10.1159 / 000358111$

23. Matsueda K, Hongo M, Tack J, Aoki H, Saito Y, Kato H: Clinical trial: dose-dependent therapeutic efficacy of acotiamide hydrochloride (Z-338) in patients with functional dyspepsia - $100 \mathrm{mg}$ t.i.d. is an optimal dosage. Neurogastroenterol Motil. 2010, 22:618-e173. 10.1111/j.1365-2982.2009.01449.x

24. Tack J, Masclee A, Heading R, et al.: A dose-ranging, placebo-controlled, pilot trial of acotiamide in patients with functional dyspepsia. Neurogastroenterol Motil. 2009, 21:272-80. 10.1111/j.1365-2982.2009.01261.x

25. Behera R, Sethi S: Efficacy and safety assessment of acotiamide and Levosulpiride in functional dyspepsia . J Dent Med Sci. 2017, 16:53-57.

26. Narayanan V, Bhargava A, Pallewar S: Real world efficacy and tolerability of acotiamide, in relieving mealrelated symptoms of functional dyspepsia. J Gastrointest Dig Syst. 2018, 8:553. 10.4172/2161-069X.1000553

27. Matsueda K, Hongo M, Tack J, Saito Y, Kato H: A placebo-controlled trial of acotiamide for meal-related symptoms of functional dyspepsia. Gut. 2012, 61:821-8. 10.1136/gutjnl-2011-301454

28. Ford AC, Moayyedi P, Black CJ, et al.: Systematic review and network meta-analysis: efficacy of drugs for functional dyspepsia. Aliment Pharmacol Ther. 2021, 53:8-21. 10.1111/apt.16072 